\title{
Phytochemical Screening and GC-MS analysis of Pavonia Zeylanica
}

\section{Authors \& Affiliation:}

Y. S. V. S. Joga Rao ${ }^{1,2}$

Annasamuel Lanka ${ }^{1}$

K. Geetha Bhavani²,

D. Ramachandran ${ }^{2}$,

H. B. Bollikolla ${ }^{2, *}$

\section{${ }^{I}$ Department of chemistry Rajah \\ RSRK RR College (Aided), Bobbili,}

AP-India

${ }^{2}$ Department of Chemistry, Acharyaa

Nagarjuna University, Guntur-

522510, AP-India.

\section{Corresponding Author}

\section{H. B. Bollikolla}

\section{Email: haribabu@anu.ac.in}

Received Date: $18^{\text {th }}$ May 2020

Accepted Date: $5^{\text {th }}$ Dec' 2020

(C) 2020. The Authors. Published under

Caribbean Journal of Science and

Technology

ISSN 0799-3757

http://caribjscitech.com/

\begin{abstract}
:
The current paper is focused to screen phytochemicals, and GC-MS from the leaves of $P$. zeylanica. This study deals with screening of phytochemicals, isolation of bioactive compound(s) and characterization partial purified and purified compounds (Silica gel Column Chromatography coupled with TLC) with the aid of GC-MS.
\end{abstract}

Keywords: Phytochemical Screening, Partial characterization, GC-MS, Pavoniazeylanica.

\section{Introduction:}

Human life has many challenges but nature has given solution to every challenge in its own way. Best things in the life offered by nature are always available free. Every essential need of a man is at his reach. Man can always reach out and acquire this immense wealth offered by nature. Nature provides medicinal remedies for all kinds of diseases ${ }^{1-4}$. The current paper explores these rich therapeutics available in Provenance of P.zeylanica. Although, it has tremendous therapeutic values and regularly used in the folklore, no scientific data is available about antibacterial efficacy of this plant.

It also known as Ceylon Swamp Mallow . It is branched, stubbly, large herb, grows up to 1-1.5 meters. Hairs have been found on Stem and leaf- and flower-stalks. Leaves are 1.5-3 cm long, 1-2.5 cm broad and Lance-shaped to ovate. However, lower leaves are 3-lobed and lobes oblong or obovate. Leaf stalks are of 1-4.5 cm long. Flowers are found singly in leaf axils and are about $1.5 \mathrm{~cm}$ long and pink in color. The length of flower stalk is about $2-4 \mathrm{~cm}$ long. Sepals are lance-shaped. Fruit is velvey, spherical and about $5 \mathrm{~mm}$. This shrub is mainly found in the countries like Srilanka, India, Pakistan, Arabia, and Tropical Africa.

The root is washed and boiled to prepare a decoction. This preparation is thoroughly sieved, and used to control dysentery, and abdominal pain. The root decoction with turmeric is also used to subside itching. Paste made with fresh young leaves is applied over wounds as an ointment to control inflammation and other skin infections. The present study is made to screen, isolate, partially characterize antibacterial compounds from this plant. 


\section{Materials and Methods: \\ Chemicals:}

In order to investigate the phytochemicals, all the chemicals of several standard assays are being employed in the present study.

\section{Phytochemical analysis of plant extracts:}

The chemical components present in the plant are categorized into primary and secondary metabolites. Primary metabolites are responsible for growth and development of the plant, while secondary metabolites involve in functions other than growth. Secondary metabolites are also called natural products ${ }^{6}$. Different standard procedures are employed in the present study to detect a particular Phytochemical in the plant extract.Salkowski test described by Muhitet al.is employed to detect Terpenoids in the present study ${ }^{7}$. Reddish-brown tinge appearance at the interface of the invisible layers after the addition of sulfuric acid infers the presence of terpenoids in the plant sample.

Tests described by Leonard and Jean (1960), are employed to detect Sterols ${ }^{8}$. Change of color into green or violet infers the presence of steroid nucleus. Procedure adopted by Kokate et al. is employed in the present study to dectect Saponins ${ }^{9}$. The formation of emulsion infers the presence of saponins in the extract. Chemical tests like Mayer's, Wagner's and Hager's as described by Al-Amin et al. and Schaneberg and Khan are employed to detect alkaloids ${ }^{10,}$ 11 .

The formation of creamy white precipitate in Mayer's test, development of brown color precipitate in Wagner's test, and formation of dark yellow precipitate in Hager's test are indications of the presence of Alkaloids in the test sample. Shinoda test described by I. Ahmed et al. is employed in the present study to detect Flavonoids ${ }^{12}$. Formation of scarlet color infers the presence of Keller-killani test described by Edeogaet al. is used to detect Cardiac glycosides in the present study ${ }^{13}$. The development of greenish blue color infers the presence of Cardiac glycosides in the test sample. The presence of carbohydrates is detected by Molish's reagent procedure described by Qureshi $e t$ $a l .{ }^{14}$. Purple color ring formation at the interface of the two liquids assumes the presence of carbohydrates. Benedict's reagent and Fehling's reagent are used in the present study to detect reducing sugars. The procedure described by Rahman et al. is employed in the present study ${ }^{15}$. The appearance of brick red precipitate at the bottom of the test tube indicates the presence of reducing sugars in the extract with Benedict's reagent.

\section{Purification of Bioactive compounds:}

Majority of the bioactive compounds are present in complex mixtures. Therefore, isolation and identification of bioactive compounds from the crude plant extracts is the crucial step for the development of new therapeutics. The process of purification comprises of two steps i.e. removal of inactive compounds from the crude and isolation of the compound responsible for the antibacterial activity of the plant. TLC monitored silica gel column chromatography is used for the purification of bioactive compounds in the present study.

\section{GC - MS Analysis:}

Gas chromatography-mass spectrometry (GC-MS) is an analytical method used to detect various chemical constituents in a sample. It offers an overview about the plant extract in terms of its chemical constituents. The present study was carried out at the Department of Science and Technology (DST), Sophisticated Analytical Instrument Facility, Indian Institute of Technology (SAIF, IIT Mumbai).

\section{Results and Discussion: Phytochemical screening:}

Inspection of Phytochemical constituents of methanol extract of $P$. zeylanica reveals the presence of glycosides, phenolic compounds, carbohydrates and reducing sugars. Positive results of Keller-killani test, Shinoda test and test for phenolic compounds indicate the presence of glycosides, flavonoids, and phenolic compounds respectively. Positive results of Benedict's and Fehling's suggests that sugar moiety is a reducing equivalent. Alkaloids, steroids, 
Terpenoids and saponins are absent in this plant (Figure 1 and Table 1). The results of the present study infer that $P$. zeylanicais a potent to obtain biologically important phytochemicals that aid in preparing safe eco-friendly drugs since it shows High degree of zone of inhibition, high relative percentage of inhibition than standard antibiotics, and presence of different phytochemical constituents. Therefore, the methanol extract of $P$. zyelenica (leaves) was taken to isolate and characterize antibacterial compounds.
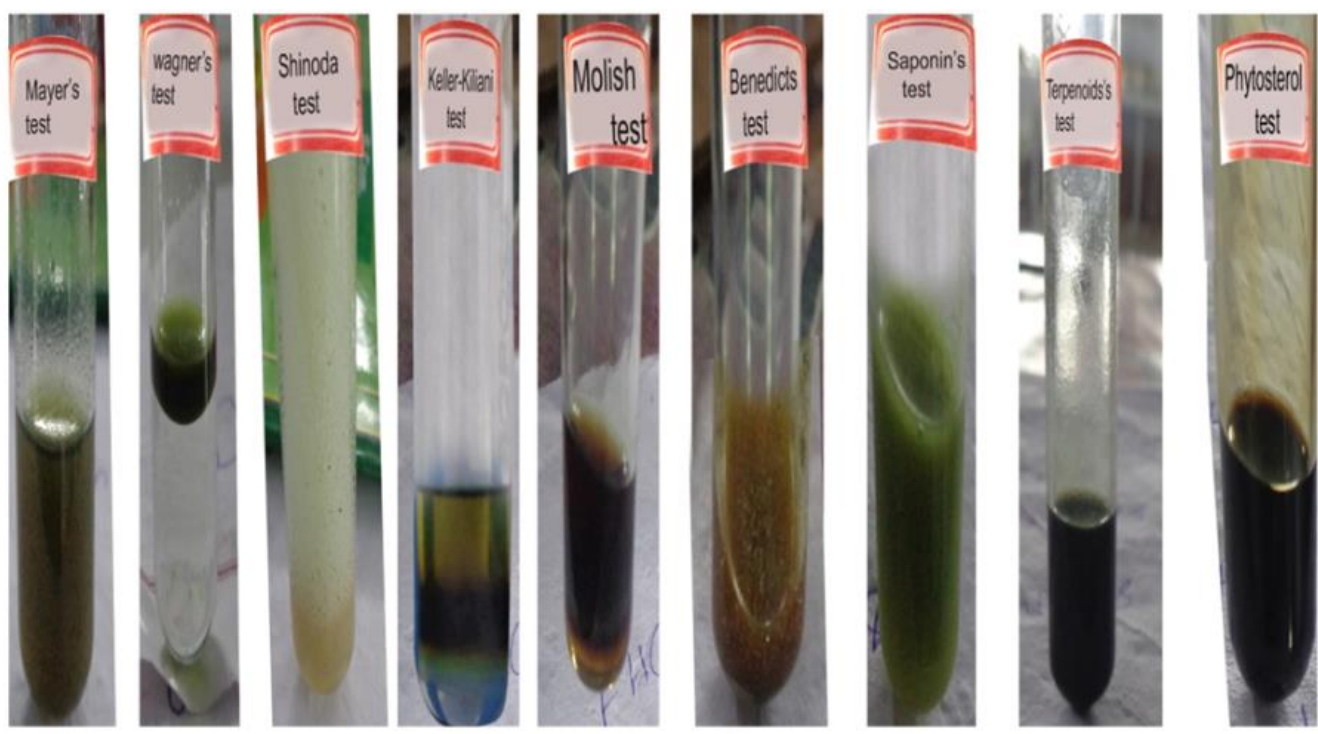

Figure 1: Phytochemical screening of P.zeylanica

Table 1: Phytochemical screening of plants under study

\begin{tabular}{|c|c|c|c|c|c|c|c|c|c|}
\hline \multirow[b]{2}{*}{ Name of the plant } & \multicolumn{9}{|c|}{ Name of the Phytochemical test } \\
\hline & $\begin{array}{l}\text { Mayer' } \\
\text { s test }\end{array}$ & $\begin{array}{l}\text { Wager' } \\
\text { s } \\
\text { test }\end{array}$ & $\begin{array}{l}\text { Shinoda } \\
\text { test for } \\
\text { flavonoi } \\
\text { ds }\end{array}$ & $\begin{array}{l}\text { Keller } \\
- \\
\text { killani } \\
\text { test }\end{array}$ & $\begin{array}{l}\text { Salkow } \\
\text {-ski } \\
\text { test }\end{array}$ & $\begin{array}{l}\text { Molis } \\
\text { h test }\end{array}$ & $\begin{array}{l}\text { Bene } \\
- \\
\text { dicts } \\
\text { test }\end{array}$ & $\begin{array}{l}\text { Test } \\
\text { for } \\
\text { phenol } \\
\text { s }\end{array}$ & $\begin{array}{l}\text { Test for } \\
\text { phytostero } \\
\text { ls }\end{array}$ \\
\hline Achyranthus aspera & - & - & + & + & - & + & + & + & - \\
\hline Blumea fistulosa & + & + & + & + & - & + & + & - & - \\
\hline $\begin{array}{l}\text { Blumeasolidaginoid } \\
\text { es }\end{array}$ & + & + & + & + & + & - & - & - & + \\
\hline Clitoriaternatea & - & - & - & + & + & + & + & - & + \\
\hline $\begin{array}{l}\text { Euphorbia indica } \\
\text { (Whole plant) }\end{array}$ & + & - & + & + & + & - & - & + & + \\
\hline $\begin{array}{l}\text { Hydrocotyle } \\
\text { rotundifolia }\end{array}$ & + & + & - & + & - & + & + & - & - \\
\hline Leonotisnepetifolia & + & + & - & + & + & + & + & - & - \\
\hline Pavoniazylenica & - & - & + & + & - & + & + & + & - \\
\hline Quisqualis indica & + & - & - & + & + & - & - & - & + \\
\hline Solanum surattense & - & - & - & + & + & + & + & - & - \\
\hline
\end{tabular}




\section{Purification:}

Silica gel column chromatography was employed to purify the plant extract in order extract antibacterial compounds. Initially, Column was run with $100 \%$ n-Hexane to remove common plant non-polar metabolites like chlorophyll and other impurities. Then, it was run with a gradient mixture of n-Hexane and Ethyl acetate (EA) of increasing polarity (0-100\% EA). 50 fractions (100 mL each) were collected and combined to 14 fractions on basis of their $R_{f}$ values. These were labeled as Pz-1-14. Among fractions studied, antibacterial activity was observed with $\mathrm{Pz}-4$ fraction. 3:7 n-Hexane: ethyl acetate elutes the active bioactive fraction ${ }^{17}$. Therefore, it was labeled as Pz-A-4 ( $4^{\text {th }}$ fraction of as an Active fraction).

Figure 2 shows the chromatogram of the different fractions studied. Fraction analysis was tabulated in Table 2. First fraction shows nine bands on TLC chromatogram. $R_{\mathrm{f}}$ values these nine bands were found between 0.08 to 0.61 . Similar results were found with Second and third fractions. Therefore, the first, second and third fractions were mixed and labeled as $\mathrm{P} z$ active fraction since they were similar in their $\mathrm{R}_{\mathrm{f}}$ values. Fourth and fifth fractions were not considered for characterization studies because no antibacterial activity was found with these fractions.

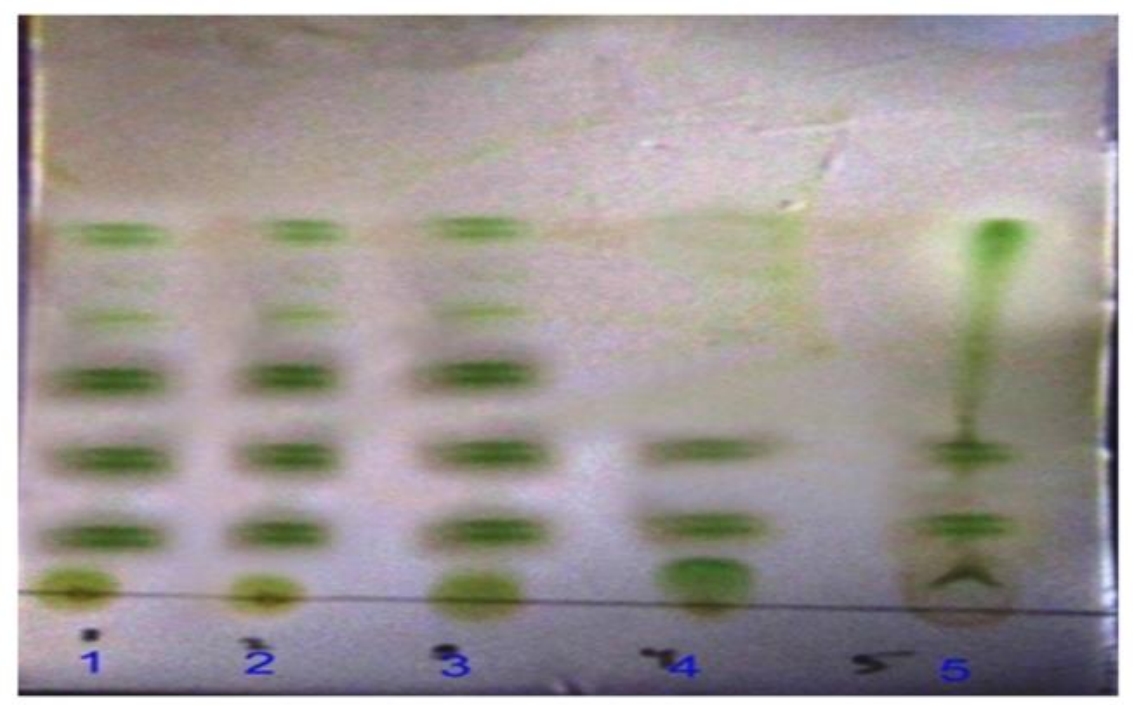

Figure 2: TLC Chromatogram of P.zeylanica (7:3 Ethyl acetate: N- Hexane fraction)

Where 1-5 represents five fractions among them 1,2 and $3^{\text {rd }}$ fractions constitue Pz-A-4 (Partially purified active fraction of $P$. zeylanica).

Table 2: P.zeylanica active (Pz-A-4) fraction analysis

\begin{tabular}{|c|c|c|}
\hline $\begin{array}{c}\text { Fraction } \\
\text { number }\end{array}$ & $\begin{array}{c}\text { Total number of } \\
\text { bands on TLC }\end{array}$ & $\begin{array}{c}\text { Rf values of each band on TLC } \\
\text { (chromatogram is read right from } \\
\text { bottom to top. }\end{array}$ \\
\hline 1 & 9 & $0.08,0.1,0.25,0.29,0.4,0.41,0.5,0.6,0.61$ \\
\hline 2 & 9 & $0.08,0.1,0.25,0.29,0.4,0.41,0.5,0.6,0.61$ \\
\hline 3 & 9 & $0.08,0.1,0.25,0.29,0.4,0.41,0.5,0.6,0.61$ \\
\hline 4 & 5 & $0.08,0.1,0.25,0.29,0.4$ \\
\hline 5 & 5 & $0.08,0.1,0.25,0.29,0.4$ \\
\hline
\end{tabular}

The TLC chromatogram (Figure 2) of the biologically active fraction (Pz-A-4) shows nine bands. It infers the presence of at least nine phytochemical constituents in active fraction. This fraction was labeled as Pavoniazeylanica Partially Purified Active Fraction (Pz-PPAF). Therefore, the active fraction was consiTensil column of $20 \mathrm{Ex} 1 \mathrm{~cm}$ size was employed to conduct further purification. To 3 grams of active fraction (BF-A-4) 
was taken and mixed with 0.5 grams of silica gel of (100 to 200 mesh size). The silica gel column was prepared as per stipulated standard practical procedure explained in materials and methods. Elution was performed with a gradient mixture of Ethyl acetate (EA) and Chloroform (chloroform) of increasing polarity (0-100\% chloroform). Totally, 50 fractions were eluted and each fraction was about $20 \mathrm{~mL}$ each. $\mathrm{R}_{\mathrm{f}}$ values of these fractions were calculated to combine similar fractions. These fifty fractions were combined to nine fractions. These fractions were labeled as Pz-A-4 (Table 3) (P.zeylanica Active fraction for characterization from 1 to 9 fractions). And considered as partially purified and subjected to further purification process. This fraction shows a single band on TLC chromatogram with $\mathrm{R}_{\mathrm{f}} 0.36$ (Figure 3 ). However, the purity of fraction need to be verified in counter-checking TLC since many plant pigments form a single band on TLC chromatogram, although they possess many compounds.

Table 3: Purification of partially purified active fraction (Pz-A-4-C)

\begin{tabular}{|c|c|c|}
\hline $\begin{array}{c}\text { Name of the } \\
\text { fraction }\end{array}$ & $\begin{array}{c}\text { Number of band } \\
\text { on TLC }\end{array}$ & $\begin{array}{c}\text { Rf } \\
\text { values }\end{array}$ \\
\hline Pz-A-4-C1 & 2 & 0.82 \\
\hline Pz -A-4-C2 & 1 & 0.72 \\
\hline Pz -A-4-C3 & 1 & 0.63 \\
\hline Pz -A-4-C4 & 1 & 0.51 \\
\hline Pz -A-4-C5 & 1 & 0.42 \\
\hline Pz -A-4-C6 & 1 & 0.32 \\
\hline Pz -A-4-C7 & 1 & 0.22 \\
\hline Pz -A-4-C8 & 1 & 0.13 \\
\hline Pz -A-4-C8 & 0 & 0 \\
\hline
\end{tabular}

In order to check the purity of fraction, counterchecking mobile phase is a handy tool. It is performed by placing the fraction spotted TLC plate in at least three different mobile phases. The three different mobile phases employed in the present study include BEA (Benzene: Ethanol: Ammonia) in 18:2:0.2, CEF (Chloroform, Ethyl acetate and Formic acid) in 10:9:2 ratio and EMW (Ethyl acetate Methanol and water) in 10:1:0.5 ratio. These three mobile phases are suitable to separate polar, middle polar and non-polar compounds respectively. Counter-checking inspection of the active fraction reveals that the Pz-A-4-C5 fraction was a pure fraction. Since it showed single band in three different mobiles phases at $\mathrm{R}_{\mathrm{f}} 0.32,0.58,0.72$, with BEA, CEF and EMW respectively (Figure 4 and Table 4). The fraction was labeled as Pavoniazeylanica Purified Active Fraction (Pz-PAF). Furthermore, it is clearly evident that the fraction Pz-A-4-C5 contains a single pure compound as $\mathrm{R}_{\mathrm{f}}$ value is increased from nonpolar to polar mobile phase without changing the number of bands in the TLC Plates. Therefore, this fraction was taken for characterization. Both Purified Active Fraction (Pz-PAF) and Partially Purified Active Fraction(Pz-PPAF) were characterized by GC-MS. Results presented in GC-MS Chromatogram reveal the presence of 11peaks in Partially Purified Active Fraction (Pz-PPAF) Figure 5. NIST library match characterizes them into 11 different phytochemical constituents. Elution has occurred between retention times (RT) ranging from 4.12 to 32.91 . The details of these compounds, Compound name, and molecular formula, Molecular Weight of the compound, Peak area percentage, and biological properties of each compound were tabulated in Table 5. 1- nonadecanol(28.31\%), 5(1-Bromo-1-methyl-2-methyl-cyclohexanol (16.6\%) and 1,2-cyclohexanedicarboxylic acid, bis(2-ethylhexyl) ester(13.97\%) were predominantly occurred among the eleven compounds characterized. Other compounds were there in very less quantity in the partially purified active fraction and were presented in Table 5 along with their biological significance. 


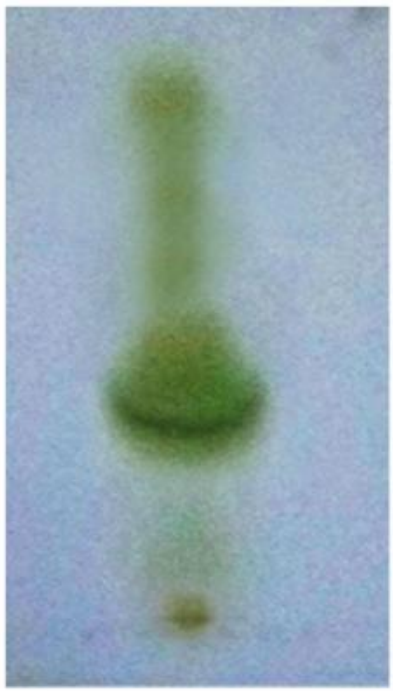

Figure 3:Purified Active Fraction of P.zeylanica(Pz-PAF)

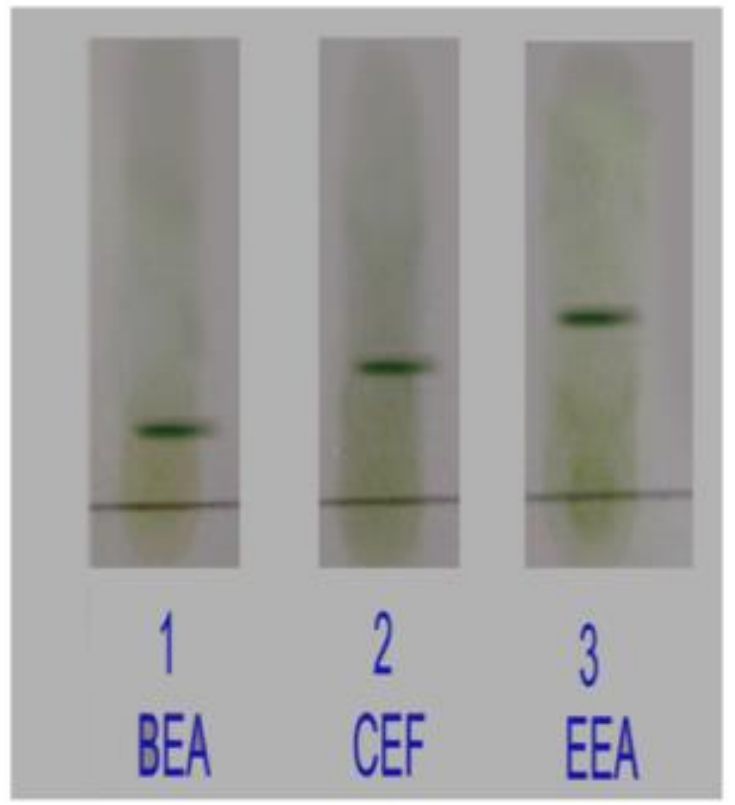

Figure 4:Purified active fraction in three different mobile phases.

Table 4: Active fraction analyses in different mobile phase

\begin{tabular}{|c|c|c|}
\hline $\begin{array}{c}\text { Name of mobile } \\
\text { phase }\end{array}$ & $\begin{array}{c}\text { Number of band } \\
\text { on TLC }\end{array}$ & Rf \\
\hline BEA & 1 & 0.32 \\
\hline CEF & 1 & 0.58 \\
\hline EMW & 1 & 0.72 \\
\hline
\end{tabular}


Table 5: GC-MS analysis of samples

\begin{tabular}{|c|c|c|c|c|c|}
\hline $\begin{array}{l}\text { Retention } \\
\text { time }\end{array}$ & Name of the compound & $\begin{array}{l}\text { Molecular } \\
\text { formula }\end{array}$ & $\begin{array}{l}\text { Molecular } \\
\text { Weight }\end{array}$ & $\begin{array}{c}\text { Peak } \\
\text { area } \%\end{array}$ & $\begin{array}{l}\text { Significance of the } \\
\text { compound }\end{array}$ \\
\hline 4.12 & 3-Decen-2-one & $\mathrm{C}_{10} \mathrm{H}_{18} \mathrm{O}$ & 154 & 1.43 & $\begin{array}{l}\text { Anti-oxidant and nontoxic } \\
\text { food favoring agent approved } \\
\text { by FDA }\end{array}$ \\
\hline 4.18 & $\begin{array}{c}\text { Pentane,2,2,4-trimethyl- } \\
\text { 4nitro }\end{array}$ & $\mathrm{C}_{8} \mathrm{H}_{17} \mathrm{NO}_{2}$ & 159.22 & 4.51 & $\begin{array}{l}\text { Cyto toxic and toxic for } \\
\text { human consumption }\end{array}$ \\
\hline 12.51 & 4-Methyl-dodec-3-en-1-ol & $\mathrm{C}_{13} \mathrm{H}_{26} \mathrm{O}$ & 198.19 & 9.78 & Function is unknown \\
\hline 13.10 & Diethyl phthalate & $\mathrm{C}_{12} \mathrm{H}_{14} \mathrm{O}_{4}$ & 222.24 & 8.67 & Antifungal and antimicrobial \\
\hline 13.85 & $\begin{array}{l}\text { 2,4,4-trimethyl-1-pentyl } \\
\text { methylphosphonofluoridate }\end{array}$ & $\mathrm{C}_{9} \mathrm{H}_{20} \mathrm{FO}_{2} \mathrm{P}$ & 210.22 & 7.88 & $\begin{array}{l}\text { In detergents and pesticides } \\
\text { preparation. }\end{array}$ \\
\hline 15.27 & $\begin{array}{l}\text { Cyclohexylmethyl undecyl } \\
\text { ester }\end{array}$ & $\mathrm{C}_{18} \mathrm{H}_{36} \mathrm{O}_{3} \mathrm{~S}$ & 332.54 & 1.43 & Antifilarial activity \\
\hline 17.88 & $\begin{array}{c}\text { Anthracene,9- } \\
\text { 10dodecyltetradecahydro }\end{array}$ & $\mathrm{C}_{26} \mathrm{H}_{48}$ & 360.65 & 6.54 & Anticancer activity. \\
\hline 25.92 & $\begin{array}{c}\text { Anthracene,9-10 } \\
\text { dodecyltetradecahydro }\end{array}$ & $\mathrm{C}_{26} \mathrm{H}_{48}$ & 360.65 & 1.04 & Anticancer activity. \\
\hline 32.22 & $\begin{array}{c}1,2- \\
\text { cyclohexanedicarboxylic } \\
\text { acid,bis(2-ethylhexyl) ester }\end{array}$ & $\mathrm{C}_{24} \mathrm{H}_{44} \mathrm{O}_{4}$ & 396.60 & 13.97 & $\begin{array}{c}\text { Alternative plasticizer and } \\
\text { cytotoxic }\end{array}$ \\
\hline 32.29 & 1- nonadecanol & $\mathrm{C}_{19} \mathrm{H}_{40} 0$ & 266.65 & 28.31 & Antimicrobial and cytotoxic \\
\hline 32.91 & $\begin{array}{l}\text { 5-(1-Bromo-1-methyl-2- } \\
\text { methyl-cyclohexanol)* }\end{array}$ & $-\mathrm{C}_{10} \mathrm{H}_{19} \mathrm{BrO}$ & 235.161 & 16.16 & Unknown functions. \\
\hline
\end{tabular}

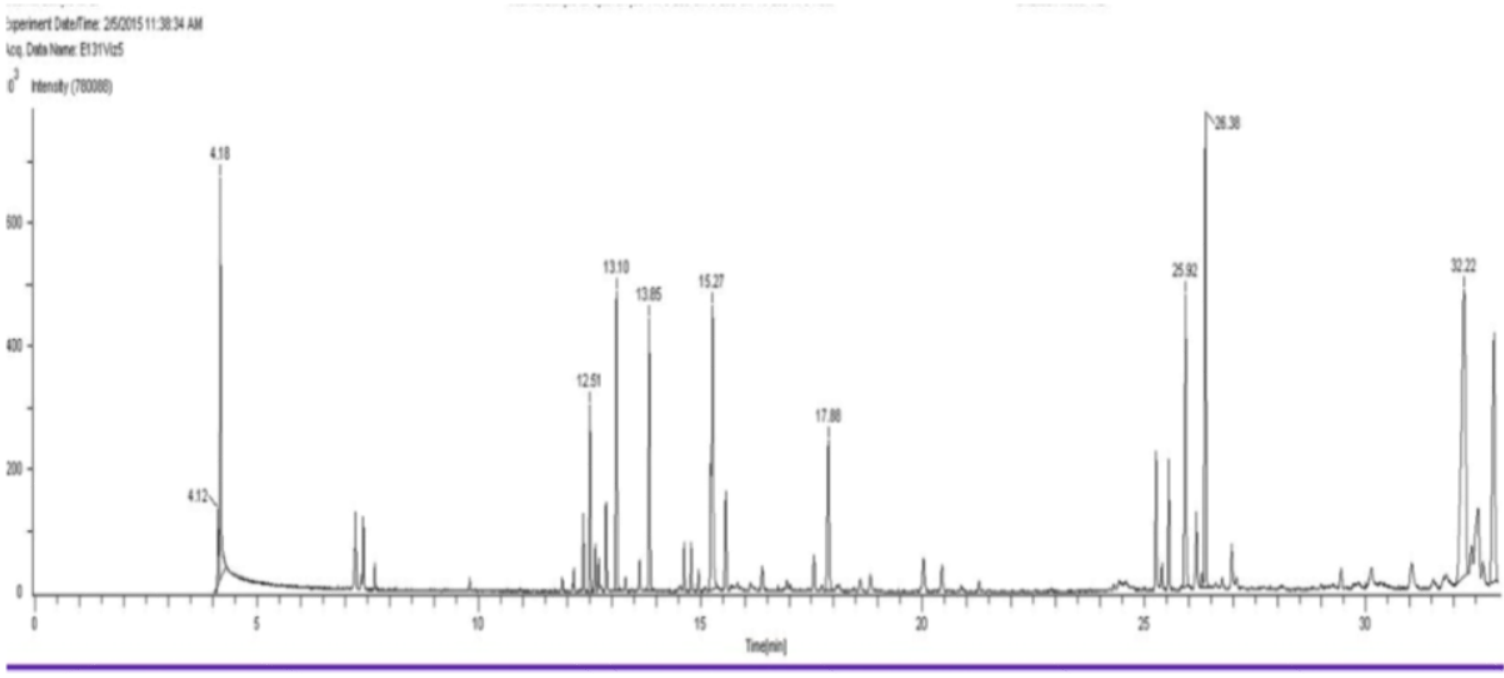

Figure 5: GC-MS Chromatogram of P.zeylanica Partially Purified Active Fraction (Pz-PPAF) 
In contrast, characterization of Pz-PAF (PavoniaZeylanica- Purified Active Fraction) reveals one compound in the fraction. GC-MS chromatogram of this fraction (Pz-PAF) showed single peak (Figure 6) and also single band on TLC (Figure 3). Elution of this compound was observed at 32.22 retention time. Further, the NIST library match characterizes the compound as 1, 2-cyclohexanedicarboxylic acid, bis(2-ethylhexyl) ester(Figures 79).

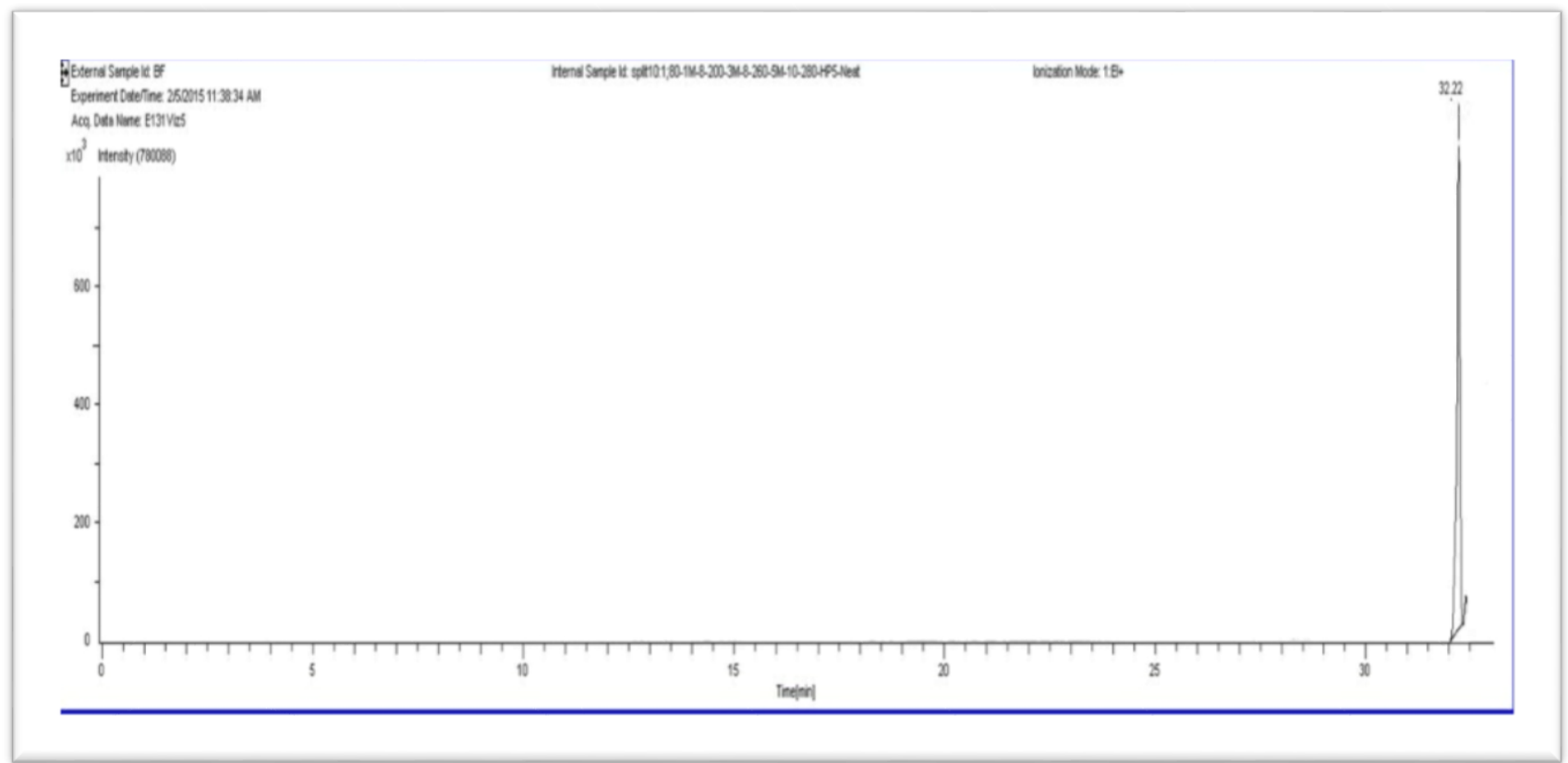

Figure 6: GC-MS Chromatogram of P.zeylanica (Pz-PAF)

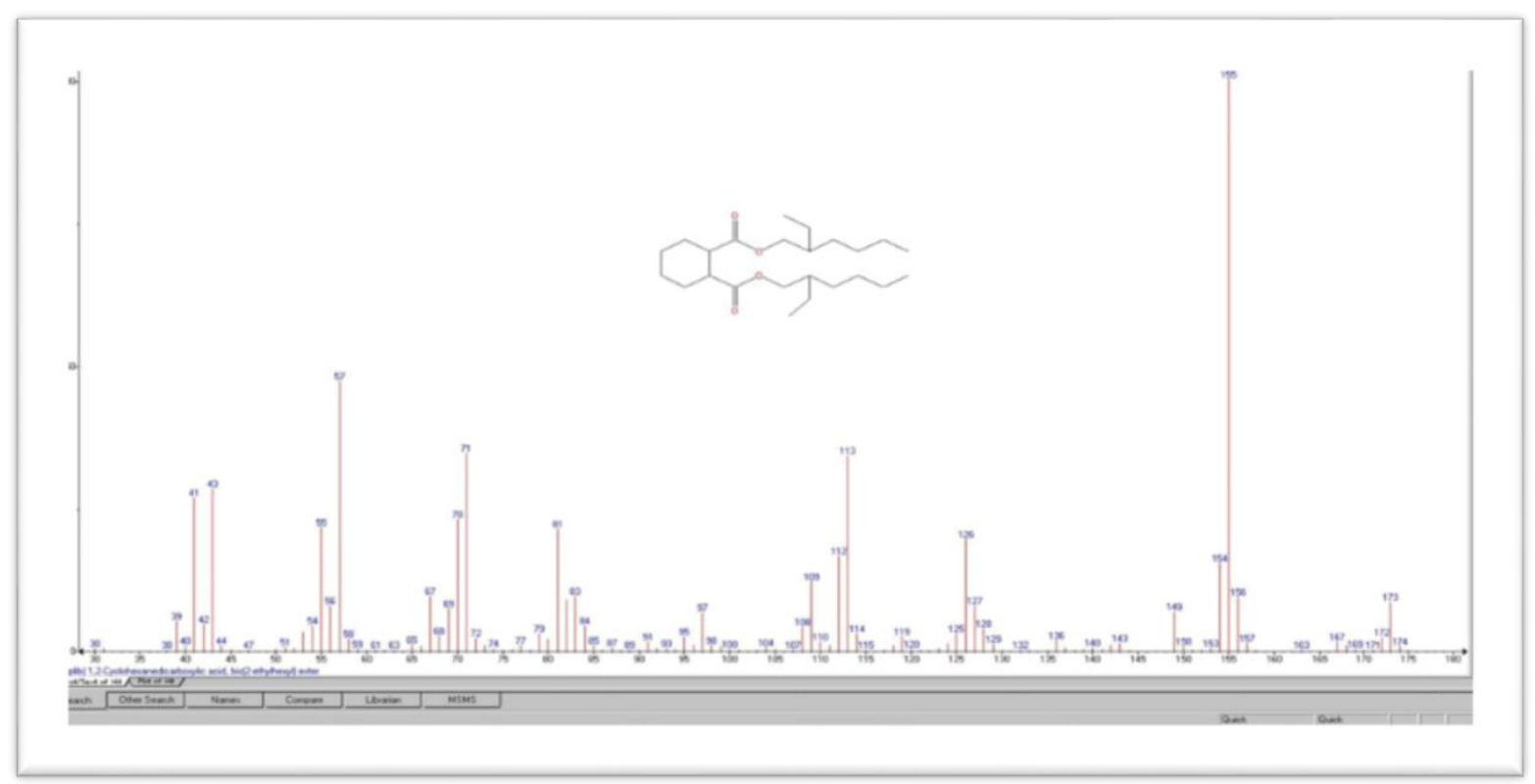

Figure 7:Mass fragmentation of purified active fraction. 


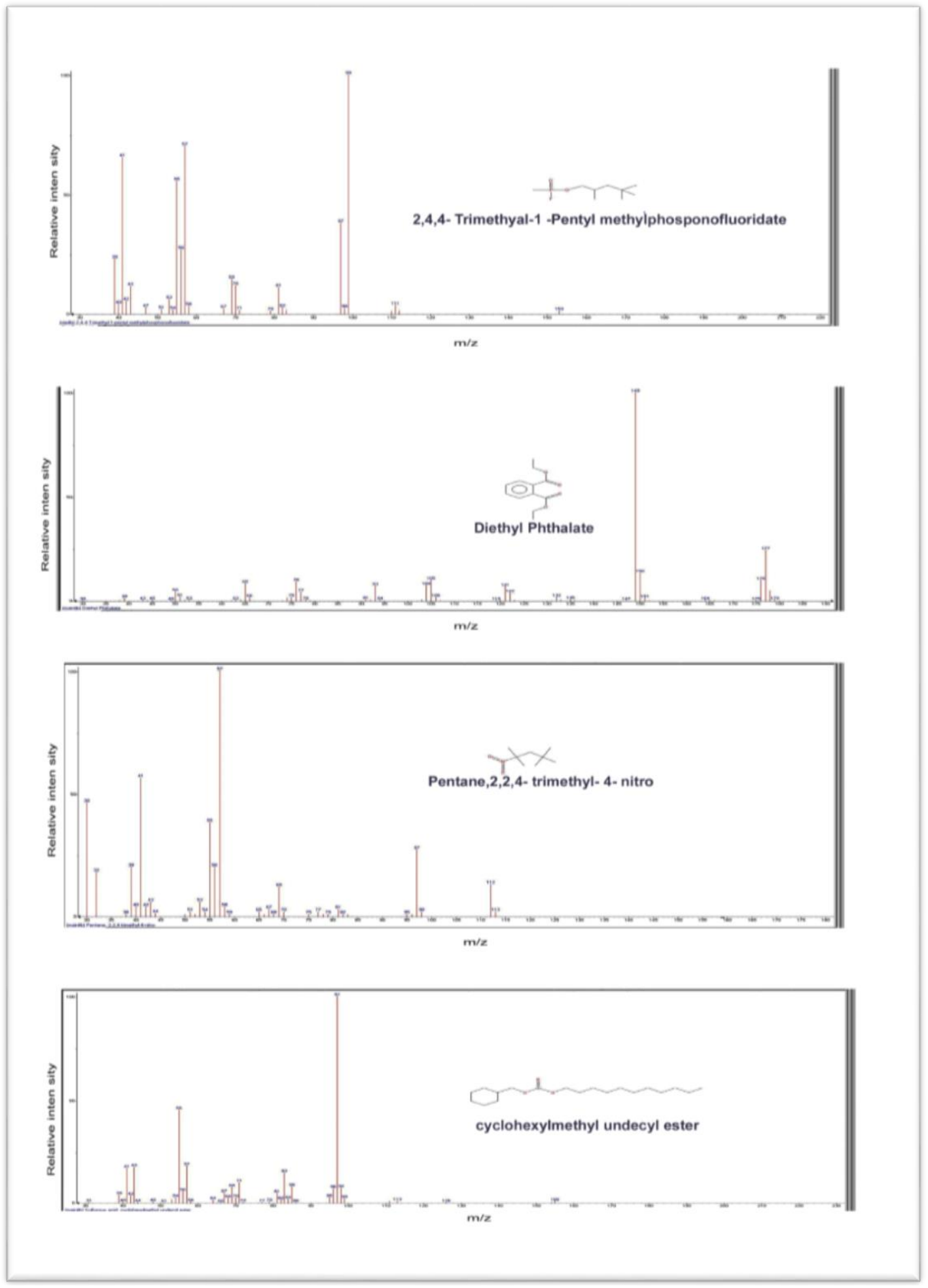

Figure 8: Phytochemical constituents of $P$. zeylanica partially purified active fraction (Pz-PPAF). 

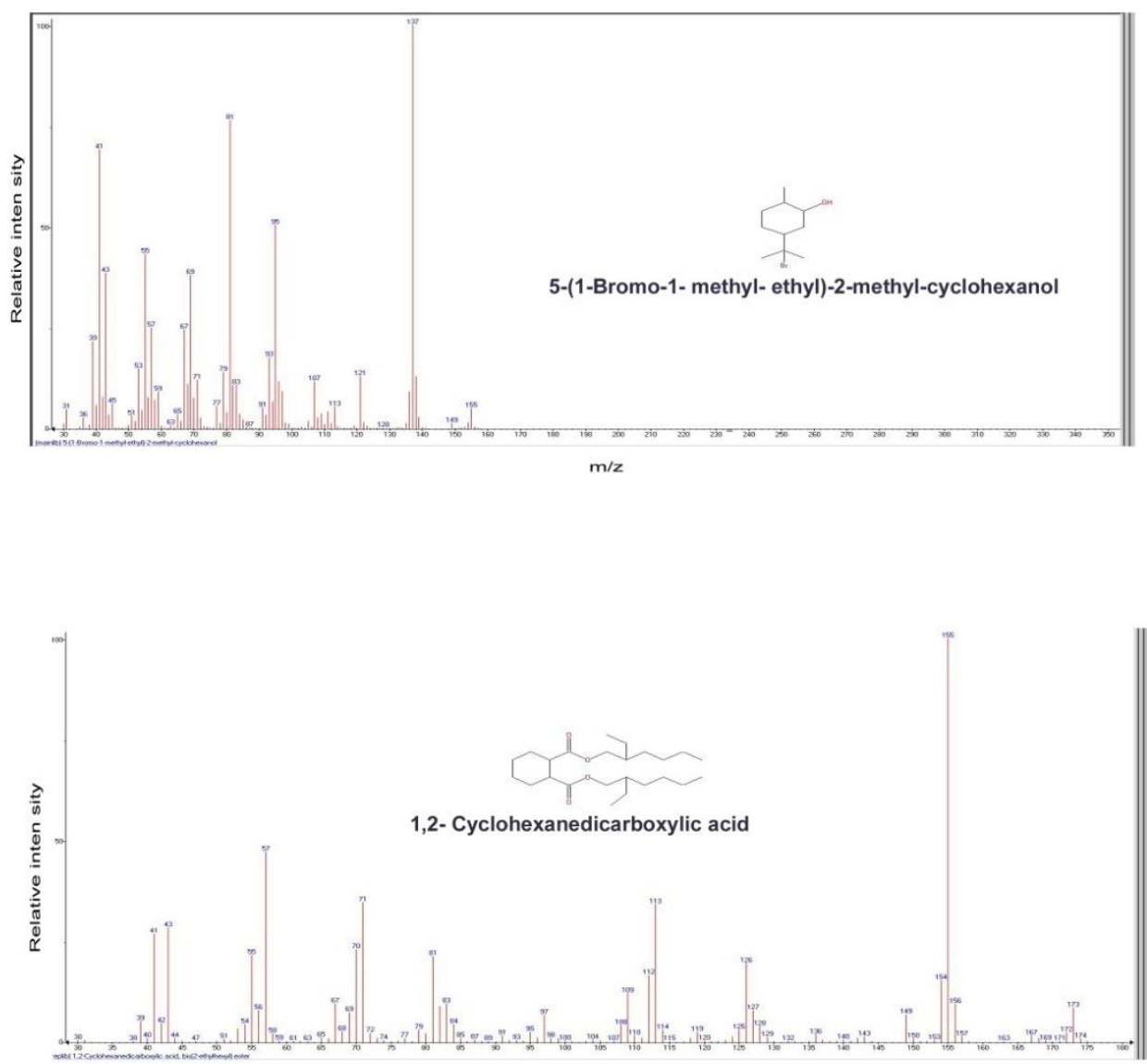

$m / z$

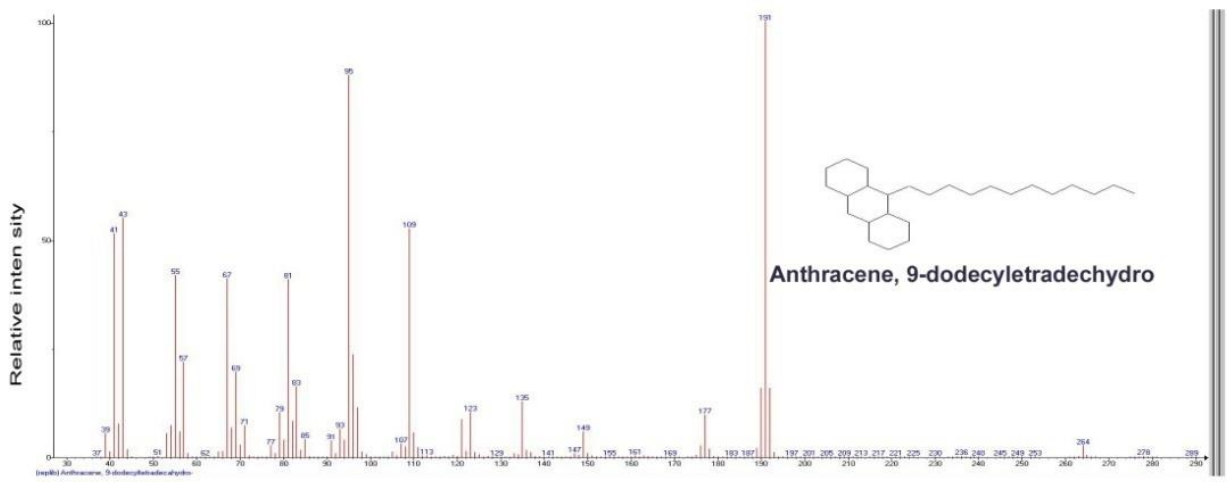

$\mathrm{m} / \mathrm{z}$

Figure 9:Phytochemical constituents of $P$. zeylanica partially purified active fraction (Pz-PPAF)

GC-MS characterization of P.zeylanicareveals the presence of 1,2 cylclohexanedicarboxylic acid, bis (2- ethyl ester (13.97\%),1- Nonadecanol (28.31\%), which were well known for their antibacterial property. On the other hand, GC- 
MS analysis of $B$. lacera reveals the presence of Thymoquinoldimethyl ether in lesser quantity. GC-MS analysis of B. balsmifera reveals the presence of 3,4,5,6,7 Hexahydro-2,5,5 trimethyl-2H-4aEthanonaphthaleneThujopsene(10.28\%), 4- ethenyl-a- 4, trimethyl-3-(1-Methylethenyl)cyclohexanemethanol (38.8\%), 3- Butyl-4- methoxyphenol methyl derivative $(12.54 \%)$ and these compounds were characterized as antimicrobial compounds ${ }^{15}$. This clearly indicates that $P$. zeylanicawas a potential plant to extract therapeutically potential chemicals.

Furthermore, 1, 2 cylclohexanedicarboxylic acid, bis (2- ethyl ester (13.97\%), 1- Nonadecanol (28.31\%) and other Phytochemicals were detected in the characterization study of plant extract. Significantly, the presence of these antibacterial phytochemical constituents justifies the folklore use of this plant in treating antibacterial infections. Different databases like Dr. Duke's phytochemical database, Pubmed, ICMR database and other databases for medicinal plants had been verified to ascertain the therapeutic potency of identified phytochemicals in the study.Inspection into these databases reveals the therapeutic value of characterized the compounds.

Remarkably, 3-Decen-2-onewas an antioxidant and food flavoring agent. USA -FDA affirmed this compound as a safe and non-toxic food additive ${ }^{18}$. Pentane, 2, 2, 4-trimethyl-4nitro was a cytotoxic compound and toxic to animals $^{19}$. Methyl-dodec-3-en-1-olwas found in $9.78 \%$ in Pz-PPAF. However, biological function of this compound was unclear. A well-known plasticizer Diethyl phthalate was also found in this extract. It needs to be asserting its presence as a Phytochemical or contamination of the glassware ${ }^{20}$. But other studies also reports diethyl phthalate from Alchornea cordifolia and its antibacterial, antifungal and antihelminthic activity ${ }^{21}$. 2, 4, 4-trimethyl-1methylphosphonofluoridate was widely used compound as an ingredient in the preparation of detergents. However, its biological function of the compound was still unknown ${ }^{22}$. Cyclohexylmethyl undecyl ester was an antifungal and antibacterial compound and it had already been extracted in other plants ${ }^{23}$. Anthracene, 9-10 dodecyltetradecahydro was-well known to possess anti-cancer properties ${ }^{24}$. 1-nonadecanol was found in high concentration $(28.31 \%)$ in the present study. But earlier it was identified in the GC-MS Analysis of chloroform extract of Croton bonplandianum. The compound was well characterized to possessantibacterial properties ${ }^{25}$. 5-(1-Bromo-1-methyl-2-methylcyclohexanol was first time identified in present study and its biological functions were still obscure.

\section{Conclusion:}

$P$. zeylanicawas a seasonal folk medicinal plant often found on roadsides. The present study first time reports its antibacterial activity and different therapeutic phytochemical constituents. Characterization studies reveal the presence of antimicrobial compounds like 1,2 cylclohexanedicarboxylic acid, bis (2- ethyl ester (13.97 \%), 1Nonadecanol $(28.31 \%)$ in the active fractions. Presence of these compound(s) justifies the folklore of this plant to treat antibacterial infections. Furthermore, the present study recommends this plant for isolation ofvarious therapeutically and biologically important phytochemicals to formulate new drugs. Nevertheless, cytotoxic and pharmacokinetic studies were indispensable to ensure clinical efficacy of isolated molecules.

\section{Reference:}

1. Samuel, L.A., Venkata, R.B., Pardha, S.M., Narashimha Rao, B., Naga, V.K., Rajagopal, S.V., Radhakrishnan, T.M. (2011). Isolation and purification of antibacterial protein from Eupatorium odoratum: A seasonal folk medicinal plant. J. Pharm. Res, 4 (12): 4641-4645.

2. Vijaya, K., Ananthan, S. (1997). Microbiological screening of Indian medicinal plants with special reference to entero pathogensll. J. Altern. Complement. Med, 3(1): 13-20.

3. Hoareau, L., DaSilva, E.J. (1999). Medicinal plants: A re-emerging health aid. Electron. J. Biotechnol, 2: 5670.

4. $\quad$ Aja, P.M., Ezeudeh, N.J., Umahi, B.G., Ugwu-Okechukwu, P.C., Enechi, O.C., Nweke, O.L., Patience, N.O. (2016). Hepato-protective effect of ethanol extract of Pterocarpus santalinoides leaf on carbon tetrachloride (CCl4) induced albino rats. Carib. j. SciTech, 4:882-895. 
5. Ceylon Swamp Mallow, flowersofindia.net, Accessed on 2020, available at http://www.flowersofindia.net/catalog/slides/Ceylon\%20Swamp\%20Mallow.html

6. Bob, B.B. (2002) Biochemistry and Molecular Biology of plants- Natural products. University of California, Berkeley- USA. $2^{\text {nd }}$ Edition, pp. 1286-1301.

7. Muhit, M.A., Tareq, S.M., Apu, A.S., Basak, D., Islam, M.S. (2010). Isolation and identification of compounds from the leaf extract of Dillenia indica Linn. Bangladesh Pharm. J, 13(1): 49-53.

8. Leonard, R.A., Jean, E.P. (1960). Color tests for the detection of sterols and estrogen on filter paper. Arch. Biochem. Biophys, 89(1):105-109.

9. Kokate, C.K. (1999). Practical pharmcognosy. Vallabh Prakashan Publication, New Delhi, India. Pp. 111116.

10. Al-Amin, M.D., Siddiqi, M.M., Akter, S., Haque, M.M., Sultana, N., Chowdhury, A.S. (2009). Isolation of quercetin-3-O-beta-D-glucopyranoside from the leaves of Azadirachta Indica and antimicrobial and cytotoxic screening of the crude extracts. Dhaka Univ. J. Sci, 60 (1): 11-14.

11. Schaneberg, B.T., Khan, I.A. (2004). Analysis of products suspected of containing Aristolochia or Asarum species. J. Ethnopharmacol, 94(2): 245-249.

12. Ahmad, I., Mehmood, Z., Mohammad, F. (1998). Screening of some Indian medicinal plants for their antimicrobial properties. J. Ethnopharmacol, 62(1): 183-193.

13. Edeoga, H.O., Okwu, D.E., Mbaebie, B.O. (2005). Phytochemical constituents of some Nigerian medicinal plants. African J. Biotechnol, 4(7): 685-688.

14. Qureshi, M.N., Stecher, G., Sultana, T., Abel, G., Popp, M., Bonn, G.K. (2011). Determination of carbohydrates in medicinal plants comparison between TLC, mf-MALDI-MS and GC-MS. J. Phytochem. Anal, 4: 296-302.

15. Rahman, M., Khatun, A., Nesa, M.L., Hossain, H., Jahan, I.A. (2015). Bioactive polyphenols from the methanol extract of Cnicus arvensis $(L)$ Roth Demonstrated Antinociceptive and Central Nervous System Depressant Activities in Mice. Evid. Based Complement. Alternat. Med, Article ID 794729: 1-7.

16. Jiang Zhi-Long, Zhou, Y., Ge Wei-Chen, Yuan, K. (2014). Phytochemical Compositions of volatile oil from blumea balsamifera and their biological activities. Pharmacongn. Mag, 10 (39): 346-352.

17. Joga Rao, Y.S.V.S., Annasamuel, L.,Hari Babu, B., Ramachandran, D. (2019). A study on antibacterial activity of Pavoniazeylanica of Malvaceae family. Carib. J. Sci. Tech., 7 (1):58-64.

18. Leandro, L.M. (2012). Chemistry and Biological activities of Terpenoids from Copaiba oleoresins. Molecules, 17(4): 3866-3889.

19. Stephen, P.A., Alistair, M. (2011). G Protein-Coupled Receptors. British J. Pharmacol, 164 (1): 5-13.

20. Api, A.M. (2001). Toxicological profile of diethyl phthalate: A vehicle for fragrance and cosmeti ingredients. Food Chem. Toxicol, 39: 97-108.

21. Mavar-Manga, H., Haddad, M., Pieters, L., Baccelli, C., Penge, A., Quetin-Leclercq, J. (2008). Antiinflammatory compounds from leaves and root bark of Alchornea cordifolia (Schumach and Thonn) Müll. Arg. J. Ethnopharmacol, 115 (1): 25-29.

22. Abercrombie, P.L., Butrow, A.B. (1998). Selected Physical Properties of Ton Container HD (Mustard) and VX, ERDEC-TR-450, U.S. Army Edgewood Research, Development and Engineering Center, Aberdeen Proving Ground, MD, Unclassified Report ADA-350462: 263-271.

23. Burkhardt, F.J., Debono, M.N., William Jr, T. W. (2003). U.S. Patent No. 20,030,220,236. Washington DC: U.S. Patent and Trademark Office.

24. Agbandje, M., Jenkins, T.C., McKenna, R., Reszka, A.P., Neidle, S. (1992). Anthracene-9, 10-diones as potential anticancer agents. Synthesis, DNA-binding and biological studies on a series of 2, 6-disubstituted derivatives. J. Med. Chem, 35(8):1418- 1429.

25. Dalli, A.K., Saha, G., Chakraborty, U. (2007). Characterization of Antimicrobial compounds from a common fern, Pterin biaurita. Indian J. Exp. Bio, 45(3): 285-290. 